\title{
Wind shear coefficient, turbulence intensity and wind power potential assessment for Dhulom, Saudi Arabia
}

\author{
Shafiqur Rehman ${ }^{\mathrm{a}}$, , Naif M. AI-Abbadi ${ }^{\mathrm{b}}$ \\ a \\ Center for Engineering Research, The Research Institute. King Fahd University of Petroleum and Minerals, Dhahran 31261, Saudi Arabia \\ Eneryy Research Institute, King Abdulaziz City for Science and Technology. P. 0. Box 6086, Riyadh 11442, Saudi Arabia \\ Received 4 November 2006; accepted 7 February 2008 \\ Available online I April 2008
}

\begin{abstract}
The study presents the local values of wind shear coefficient (WSC) estimated using wind speed measurements made at 20 , 30 and 40 m above ground level (AGL) during November 01, 1998 and October 12, 2002. The study also includes the local values of air density calculated using temperature and pressure measurement made at $2 \mathrm{~m}$ AGL during the same period. The mean wind speed above $4 \mathrm{~m} / \mathrm{s}$ and the standard deviation values were used to obtain the turbulence intensities (TI) at different heights. These local values of WSC were used to estimate the wind speed at hub-height of the wind turbines used in this study. Energy yield was calculated for a hypothetical wind form of $60 \mathrm{MW}$ installed capacity assumed to be consisting of 100 , 60 and 30 wind turbines of 600, 1000 and $2000 \mathrm{~kW}$ from DeWind, respectively.

The study recommends a value of WSC of 0.255 for the estimation of wind at different heights AGL and local air density of $1.06 \mathrm{~kg} / \mathrm{m}^{3}$ The WSC values were found to be higher during nighttime and smaller during daytime while no evident seasonal trend could be identified. In case of air density, no diurnal change was evident but a seasonal trend, with higher values in winter and lower in summer months, was evident. The annual energy yield obtained using wind speed at different hub-heights calculated with WSC $=0.255$ was found to be $10-20 \%$ higher than the yield obtained with wind speeds calculated with WSC $=0.143$ corresponding to hub-heights of 60 and $100 \mathrm{~m}$, respectively. Similarly, higher plant capacity factors (PCFs) were obtained for energy yield estimated using WSC $=0.255$ compared to that with WSC $=0.143$. Higher values of TI were obtained during day time and lower during nighttime. Furthermore, lower values were obtained during November to March and higher during rest of the year. Finally, a decreasing pattern was observed in the values of TIs with increasing height.
\end{abstract}

(C) 2008 Elsevier Ltd. All rights reserved.

Keywords: Wind shear coefficient; Turbulence intensity; Wind power assessment; Frequency distribution; Wind speed; Air density

\section{Introduction}

The modern wind turbines of today are efficient and capable of producing more power as the height of the turbine rotor increases. Wind speed increases with height and hence the power output from the wind turbines. Therefore, for accurate assessment of wind power potential at a site, one should have precise knowledge of wind

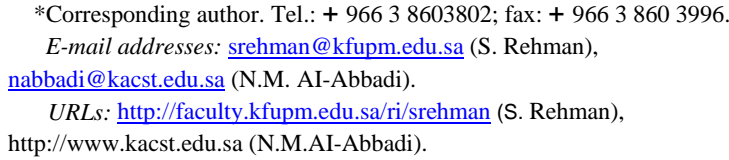

speed at different heights. This can be achieved either by measuring wind speed at the hub height of interest or by estimating using lf7th wind power law. The best and economical way is to make wind speed measurements at two or three heights for a period of at least one year and then calculate the wind shear coefficient (WSC) using measured values. This WSC then can be used with confidence to estimate the wind speed at hub height. The other important parameter that directly affects the wind power estimates is the air density.

The present study utilized the wind speed measurements made at 20, 30 and $40 \mathrm{~m}$ AGL at Dhulom in Saudi Arabia for more than three years (November 01, 1998 to October 12, 2002) and estimated the diurnal, monthly and yearly 
values of WSC. The site averaged value of WSC was then used to estimate the wind speed at different hub-heights varying from 50 to $100 \mathrm{~m}$. Finally these wind speed values were used to get the frequency distribution and the wind power output from hypothetical wind farm of $60 \mathrm{MW}$ installed capacity assumed to be developed using 100, 60, and 30 wind turbines of 600,1000 and $2000 \mathrm{~kW}$ rated power from DeWind. The local values of air density and turbulence intensity (TI) were also determined using the measured air temperature, surface pressure, mean wind speed and standard deviation.

\section{Background}

The WSCs are rarely known because the wind speed measurements are usually made at one height at most of the meteorological data collection stations around the world. There are few locations, mostly in developed countries, where wind speeds are measured at more than one height. Hall and Smith [1] reported WSC between 0.20 and 0.29 at Midwest TVP site. As given in report [2], WSCs were estimated using wind speed measurements at 40,70 and $100 \mathrm{~m}$ above ground level (AGL). Between 40 and $100 \mathrm{~m}$ a value of 0.21 was found. Smith et al. [3] reported wind annual mean values of WSCs of $0.21,0.11,0.33,0.22$, 0.28 and 0.20 for Big Spring, Ft. Davis, Iowa, Nebraska, Wisconsin and Lamar wind mast locations, respectively. In another wind resource assessment study [4], the value of WSC was reported to be 0.26 between 25 and $40 \mathrm{~m} \mathrm{AGL}$. Recently, Farrugia [5] found that the WSC varied with season with a maximum value of 0.45 in January to a minimum of 0.29 in July and August. According to Sisterton et al. [6], WSC of the order of 0.5 may be found between 30 and $150 \mathrm{~m}$ and in extreme case may reach as high as 1.0 .

In Saudi Arabia, work on wind resource assessment dates back to 1986 when a wind atlas was developed by using wind speed data from 20 locations [7]. This atlas presented the monthly mean wind speed contours and frequency distribution for all the months during the year. Rehman [8] presented the energy output and economical analysis of $30 \mathrm{MW}$ installed capacity wind farms at five coastal locations using wind machines of 600,1000 and $1500 \mathrm{~kW}$. In another study, Rehman [9] performed a detailed analysis of wind speed in terms of energy yield, effect of hub-height on energy yield, plant capacity factor (PCF), etc. for an industrial city situated on the northwest coast of Saudi Arabia. The long-term wind speed at the site was $4.63 \mathrm{~m} / \mathrm{s}$, which reached more than $5.0 \mathrm{~m} / \mathrm{s}$ at $50 \mathrm{~m} \mathrm{AGL}$. Moreover, the frequency distribution showed that a wind speed of $3.5 \mathrm{~m} / \mathrm{s}$ and above was available for $59 \%$ of the time during entire year at $10 \mathrm{~m} \mathrm{AGL}$. With growing global awareness of the usage of clean sources of energy, wind energy in particular, a lot of work is being carried out in Saudi Arabia, as can be seen from [10-13].

\section{Site and data description}

The meteorological data (wind speeds, wind direction, air temperature, relative humidity, surface station pressure, global solar radiation) were collected at Dhulom by King Abdulaziz City for Science and Technology (KACST), Riyadh, Saudi Arabia. The latitude, longitude and altitude of the site are $22.74^{\circ}, 42.18^{\circ}$ and $1117 \mathrm{~m}$ above mean sea level, respectively. The data was collected during the period from November 01, 1998 to October 12, 2002. The $40 \mathrm{~m}$ tall wind mast at Dhulom site was installed inside a fenced area owned by Western SCECO. The west anchors were located $5 \mathrm{~m}$ from the north to south of the fence. There were no barriers or obstacles about $200 \mathrm{~m}$ around the tower. There were some buildings that housed the diesel generators about $300 \mathrm{~m}$ away and west of the tower.

Data was recorded every $30 \mathrm{~min}$ on a removable data card. The wind speed data was collected at 20,30 , and $40 \mathrm{~m}$ above the ground. At each height two sensors were installed (opposite to each other) and recorded data was tagged as WS1 \& WS2 at $20 \mathrm{~m}$, WS 3 \& WS4 at $30 \mathrm{~m}$, and WS5 \& WS6 at $40 \mathrm{~m}$. The wind direction data was recorded at 30 and $40 \mathrm{~m}$ as WD1 and WD2, respectively. The surface air temperature $\left({ }^{\circ} \mathrm{C}\right)$, relative humidity $(\%)$, surface station pressure (in of $\mathrm{Hg}$ ), and global solar radiation $\left(\mathrm{W} / \mathrm{m}^{2}\right)$ data was collected at $2 \mathrm{~m}$ above the ground surface. The operating ranges and accuracies of various sensors used for the measurements are given in Table 1.

\section{Estimation of WSCs and air density}

The WSC $\alpha$ was calculated using the following equation reported by Farrugia [5]:

$\alpha=\frac{\ln \left(v_{2}\right)-\ln \left(v_{1}\right)}{\ln \left(z_{1}\right)-\ln \left(z_{1}\right)}$,

where $v_{1}$ and $v_{2}$ are the wind speeds at heights $z_{1}$ and $z_{1}$, respectively. These values of $\alpha$, calculated using Eq. (1), were used to find the annual, seasonal, and half-hourly means. The air density was calculated using the following equation given in Ref. [14]:

$$
\rho=\frac{P}{R \times T} \mathrm{~kg} / \mathrm{m}^{3},
$$

where $P$ is the air pressure $\left(\mathrm{Pa}\right.$ or $\left.\mathrm{N} / \mathrm{m}^{2}\right) ; R$ the specific gas constant for air $(287 \mathrm{~J} / \mathrm{kg} \mathrm{K})$; and $T$ the air temperature in degrees Kelvin $\left({ }^{\circ} \mathrm{C}+273\right)$. The wind speed at hub height was calculating using wind power law, as used by Farrugia [5].

$$
v_{2}=v_{1}\left(\frac{z_{2}}{z_{1}}\right)^{\alpha} \text {, }
$$

where $v_{1}$ and $v_{2}$ are the wind speeds at heights $z_{1}$ and $z_{2}$, respectively, and $\alpha$ is the WSC. 
Table 1

Operating ranges and accuracies of various sensors used for data collection

\begin{tabular}{|c|c|c|c|c|}
\hline S. no. & Parameter & Sensor type & Operating range & Accuracy \\
\hline 1. & Wind speed & NRG \#40 maximum anemometer & $1.0-96.0 \mathrm{~m} / \mathrm{s}$ & $0.1 \mathrm{~m} / \mathrm{s}$ \\
\hline 2. & Temperature & NRG \#110S with radiation shield & $-40.0-52.5^{\circ} \mathrm{C}$ & $\pm 1.11^{\circ} \mathrm{C}$ \\
\hline 3. & Pressure & NRG \#BP20 barometric pressure sensor & $15.0-115 \mathrm{kPa}$ & $\pm 1.5 \mathrm{kPa}$ Maximum \\
\hline 4. & Relative humidity & $\mathrm{RH}-5$ & $0-95 \%$ & $\pm 5 \%$ \\
\hline 5. & Wind direction & 200 series wind vane & $0-360$ & N.A. \\
\hline 6. & Global solar radiation & Li-Cor \#LI-200SA Pyranometer & $0-3000 \mathrm{~W} / \mathrm{m}^{2}$ & $\pm 3 \%$ \\
\hline
\end{tabular}

Table 2

Site statistics for Dhulom station during 1998-2002

\begin{tabular}{|c|c|c|c|c|c|}
\hline Parameters & Units & Min. & Max. & Mean & $\%$ Of values \\
\hline Wind speed (WSI at $20 \mathrm{~m}$ ) & $\mathrm{m} / \mathrm{s}$ & 0 & 24.6 & 5.1 & 99.57 \\
\hline Wind speed (WS2 at $20 \mathrm{~m}$ ) & $\mathrm{m} / \mathrm{s}$ & 0 & 24.5 & 4.7 & 99.18 \\
\hline Wind speed (WS3 at $30 \mathrm{~m}$ ) & $\mathrm{m} / \mathrm{s}$ & 0 & 22.9 & 5.5 & 99.40 \\
\hline Wind speed (WS4 at $30 \mathrm{~m}$ ) & $\mathrm{m} / \mathrm{s}$ & 0 & 23.3 & 5.3 & 86.83 \\
\hline Wind speed (WS5 at $40 \mathrm{~m}$ ) & $\mathrm{m} / \mathrm{s}$ & 0 & 23.9 & 5.9 & 99.60 \\
\hline Wind speed (WS6 at $40 \mathrm{~m}$ ) & $\mathrm{m} / \mathrm{s}$ & 0 & 24.2 & 5.8 & 87.89 \\
\hline Wind power density, WPD 1 & $\mathrm{~W} / \mathrm{m}^{2}$ & 0 & 7513 & 134 & 99.57 \\
\hline Wind power density, WPD2 & $\mathrm{W} / \mathrm{m}^{2}$ & 0 & 7449 & 105 & 99.18 \\
\hline Wind power density, WPD3 & $\mathrm{W} / \mathrm{m}^{2}$ & 0 & 6449 & 159 & 99.40 \\
\hline Wind power density, WPD4 & $\mathrm{W} / \mathrm{m}^{2}$ & 0 & 6739 & 137 & 86.83 \\
\hline Wind power density, WPDS & $\mathrm{W} / \mathrm{m}^{2}$ & 0 & 7245 & 187 & 99.60 \\
\hline Wind power density, WPD6 & $\mathrm{W} / \mathrm{m}^{2}$ & 0 & 7484 & 180 & 87.89 \\
\hline Wind direction (WD1), degrees from North & Degrees & 0 & 359 & 128 & 99.63 \\
\hline Wind direction (WD2), degrees from North & Degrees & 0 & 359 & 145 & 99.86 \\
\hline Temperature & $\mathrm{C}$ & 0.5 & 42.7 & 24.7 & 83.28 \\
\hline Global solar radiation & $\mathrm{W} / \mathrm{m}^{2}$ & 1.0 & 1157.5 & 494.2 & 50.55 \\
\hline Pressure & in of $\mathrm{Hg}$ & 26.71 & 27.84 & 27.01 & 75.12 \\
\hline Relative humidity & $\%$ & 15 & 100 & 38.04 & 14.63 \\
\hline
\end{tabular}

** Statistics for 62,327 records for the period from November 01, 1998-October 12, 2002.

\section{Results and discussion}

The site statistics of meteorological parameters is summarized in Table 2. These averages were obtained using all the data collected over entire data collection period. The last column of Table 2 gives the percent of data values used in the statistical calculation for each parameter. At $20 \mathrm{~m} \mathrm{AGL}$ the mean wind speeds were found to be 5.1 and $4.7 \mathrm{~m} / \mathrm{s}$ corresponding to two wind speed sensors while maximum remained about $25 \mathrm{~m} / \mathrm{s}$. These averages were obtained using $99.5 \%$ of the valid measured values as shown in the last column of the Table 2. At $30 \mathrm{~m}$ AGL the wind speeds were 5.5 and $5.3 \mathrm{~m} / \mathrm{s}$ corresponding to WS3 and WS4 wind speed sensors, respectively. In this case also, almost $100 \%$ of the measured values were used to obtain the mean wind speed. At $40 \mathrm{~m}$ AGL the wind speed values corresponding to WS5 and WS6 sensors were 5.9 and $5.8 \mathrm{~m} / \mathrm{s}$. In case of WS5 only $88 \%$ of the measured values were found to be correct and used in the calculation of its mean. The respective values of mean wind direction at 30 and $40 \mathrm{~m}$ heights were found to be $128^{\circ}$ and $145^{\circ}$ from North. The wind power density calculated using $30 \mathrm{~min}$ average wind speed were 134,159 and $187 \mathrm{~W} / \mathrm{m}^{2}$ at 20,30 and $40 \mathrm{~m} \mathrm{AGL}$, respectively.

At Dhulom, the temperature was found to vary between a minimum of $0.5^{\circ} \mathrm{C}$ and a maximum of $42.7^{\circ} \mathrm{C}$, while the mean remained as $24.7^{\circ} \mathrm{C}$. The mean values of global solar radiation, surface pressure, and the relative humidity were found to be $494.2 \mathrm{~W} / \mathrm{m}^{2}\left(5.93 \mathrm{~kW} \mathrm{~h} / \mathrm{m}^{2} /\right.$ day $), 27.01$ in of $\mathrm{Hg}$, and $38 \%$, respectively. The detailed discussion on the results is presented in terms of annual, seasonal, and diurnal variation of WSCs and air density in the forthcoming paragraphs.

\subsection{Wind shear characteristics}

The WSCs were calculated using Eq. (1) and six pairs of wind speeds, three on each side of the wind measurement mast. The WSC calculated between 30 and 20, 40 and 30, and 40 and $20 \mathrm{~m}$ using wind speed pairs WS3 and WS1, WS5 and WS3, and WS5 and WS1 were designated as $\alpha_{1}$, $\alpha_{2}$, and $\alpha_{3}$, respectively, while those calculated using wind speed pairs WS4 and WS2, WS6 and WS4, and WS6 and WS2 were named as $\alpha_{4}, \alpha_{5}$, and $\alpha_{6}$. The averages of these six 
coefficients over entire period of data collection are summarized in Table 3.

The mean values of $\alpha_{1}$ obtained using long-term mean wind speeds WS3 and WS1 was 0.181 , as can be seen from Table 3 . The mean WSC between 40 and $30 \mathrm{~m}$ was 0.239 while between 40 and 20 it was 0.205 . The WSCs were also calculated for each year using yearly mean values of wind speeds. The variation of $\alpha_{1}$ to $\alpha_{3}$ values with year is shown in Fig. 1. As seen from this figure, the maximum value of $\alpha_{1}(0.22)$ was observed in the year 2001 and minimum of 0.10 in 2000 , while the overall mean during all years was found to be 0.181 . The maximum value of $\alpha_{2}$ (0.32) was observed in 2000 while minimum of 0.20 in 2002. The maximum value of $\alpha_{3}(0.22)$ was found in 2001 while minimum of 0.19 in 2000 . The seasonal variation of WSCs is shown in Fig. 2. As seen from Fig. 2, no set pattern was observed in the values WSCs but it can be said that lower values were observed in summer months and higher in winter months.

The diurnal variation of $\alpha_{1}, \alpha_{2}$, and $\alpha_{3}$ is shown in Fig. 3 . From this figure, it is evident that the heating and cooling cycle of the air adjacent to the earth during $24 \mathrm{~h}$ of the day influences the WSCs. During early hours of the day i.e. between 00:00 and 07:00 h, higher and almost constant values of $\alpha_{1}, \alpha_{2}$, and $\alpha_{3}$ were observed while from $07: 00 \mathrm{~h}$

Table 3

Wind shear coefficients calculated using half-hourly mean values of wind speeds at different heights

\begin{tabular}{ll}
\hline Wind shear between & $\begin{array}{l}\text { Based on long-term } \\
\text { mean wind speed }\end{array}$ \\
\hline$\alpha_{1}-30$ and $20 \mathrm{~m}$ (WS3 and WS1) & 0.181 \\
$\alpha_{2}-40$ and $30 \mathrm{~m}$ (WS5 and WS3) & 0.239 \\
$\alpha_{3}-40$ and $20 \mathrm{~m}$ (WS5 and WS1) & 0.205 \\
$\alpha_{4}-30$ and $20 \mathrm{~m}$ (WS4 and WS2) & 0.293 \\
$\alpha_{5}-40$ and $30 \mathrm{~m}$ (WS6 and WS4) & 0.296 \\
$\alpha_{6}-40$ and $20 \mathrm{~m}$ (WS6 and WS2) & 0.294 \\
\hline
\end{tabular}

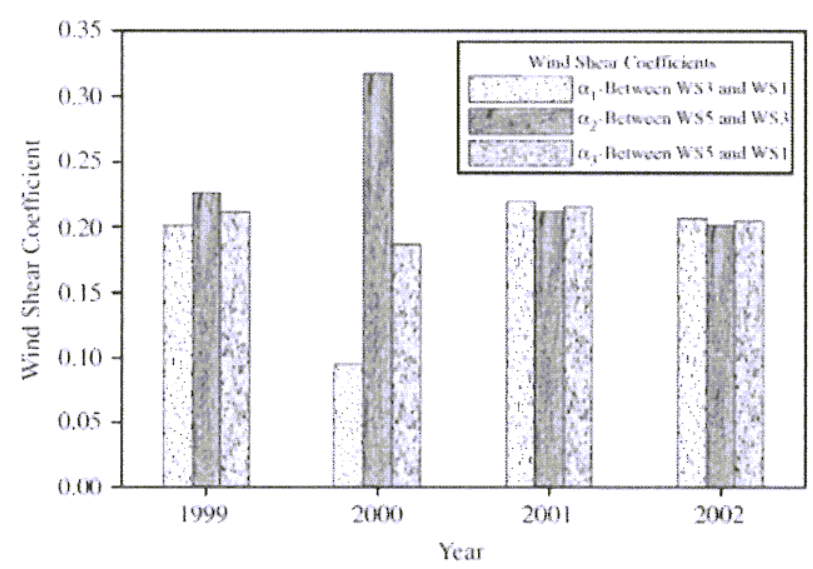

Fig. 1. Yearly variation of wind shear for Dhulom city obtained using half-hourly mean values of the wind speed on the left side of the tower.

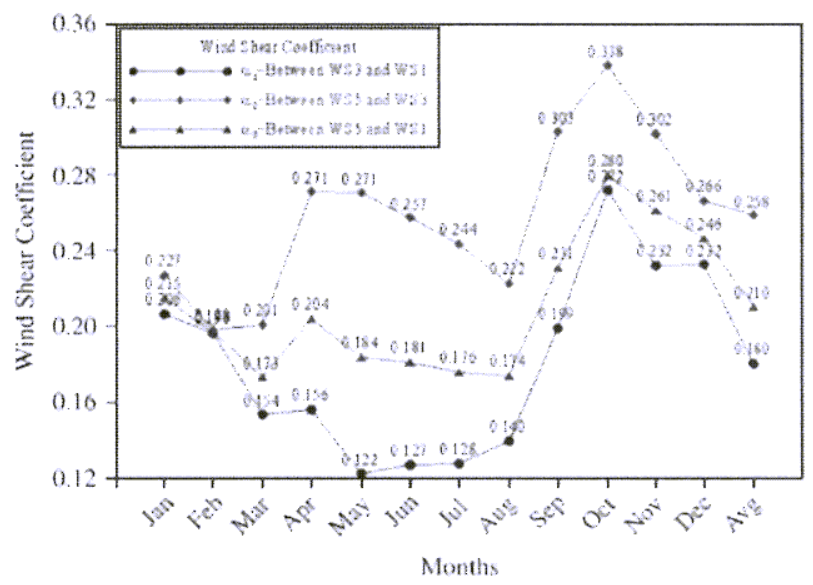

Fig. 2. Monthly variation of wind shear for Dhulom.

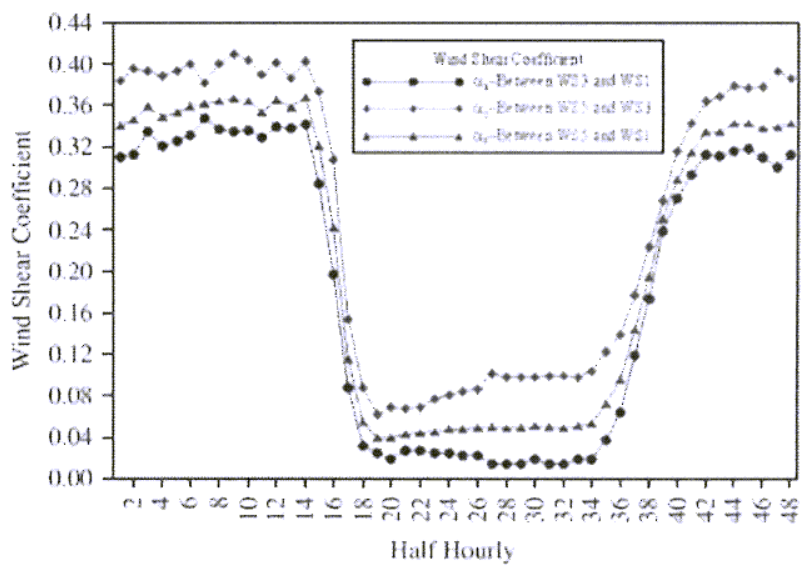

Fig. 3. Diurnal variation of wind shear for Dhulom

onwards, as heating of the ground surface and the air above it took place, these values started decreasing and after reaching a minimum at 09:00 h remained almost constant up to $17: 00 \mathrm{~h}$. After $17: 00 \mathrm{~h}$, these values again started increasing and after reaching a maximum at 21:00 h showed a constant pattern during rest of the night hours, which may be accounted for cooling of the ground surface and the air above it.

\subsection{Air density characteristics}

The air density is an important parameter whereas wind power density calculation is concerned. Denser the air, the higher is the wind power density and vice versa. In the present paper, the air density was calculated using the measured values of temperature and pressure recorded near ground surface over the entire period of data collection. The mean values of air density at different heights varied between a minimum of $1.0 \mathrm{~kg} / \mathrm{m}^{3}$ and a maximum of $1.17 \mathrm{~kg} / \mathrm{m}^{3}$ while the mean remained as $1.06 \mathrm{~kg} / \mathrm{m}^{3}$. 
The annual mean values of the air densities were computed for all the years of data collection period and were found to be around $1.06 \mathrm{~kg} / \mathrm{m}^{3}$. There was no change in the yearly mean values of the density. The overall mean value of air density at Dhulom was found to be $1.06 \mathrm{~kg} / \mathrm{m}^{3}$ and is recommended to be used for all practical purposes. The monthly mean values of air density were found high during winter and smaller during summer season, though the change was insignificant. The air density was found to vary very slightly during day and night cycle. Slightly higher values were observed during night and early morning hours compared to those during day light hours

\subsection{Wind rose and frequency distribution}

The wind rose diagram provides useful information on the prevailing wind direction and availability of directional wind speed in different wind speed bins. The wind roses were constructed using the measurements of wind speeds and corresponding wind directions. Fig. 4 show the wind rose diagram constructed using hourly mean wind speed and wind direction at $40 \mathrm{~m} \mathrm{AGL}$. Similar type of wind roses were constructed for wind speeds at other heights calculated using WSCs of 0.143 and 0.255 . The annual frequency distributions for wind speed obtained using WSC $=0.255$ and 0.143 are shown by wind frequency distribution curves in Figs. 5 and 6, respectively.

Wind speed remained $85 \%, 74 \%$ and $60 \%$ of the time above 3,4 and $5 \mathrm{~m} / \mathrm{s}$, respectively, at $40 \mathrm{~m} \mathrm{AGL}$, as can be seen from Fig. 5 while at $60 \mathrm{~m}$ the respective frequencies were found to be $88 \%, 78 \%$ and $67 \%$. At 80 and $100 \mathrm{~m}$ these values were found to be $90 \%, 81 \%, 71 \%$ and $91 \%$, $83 \%, 73 \%$ above 3,4 and 5 . This implies that at Dhulom, a wind turbine with a hub-height of $60 \mathrm{~m}$ and cut-in-wind speed of $4 \mathrm{~m} / \mathrm{s}$ can produce energy for $78 \%$ of time during entire year.

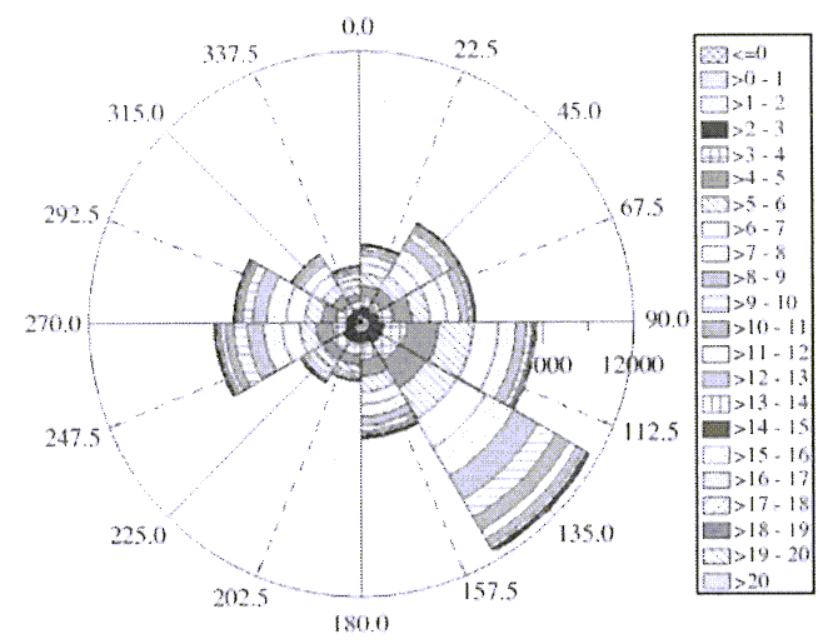

Fig. 4. Wind rose diagram at $40 \mathrm{~m}$ AGL

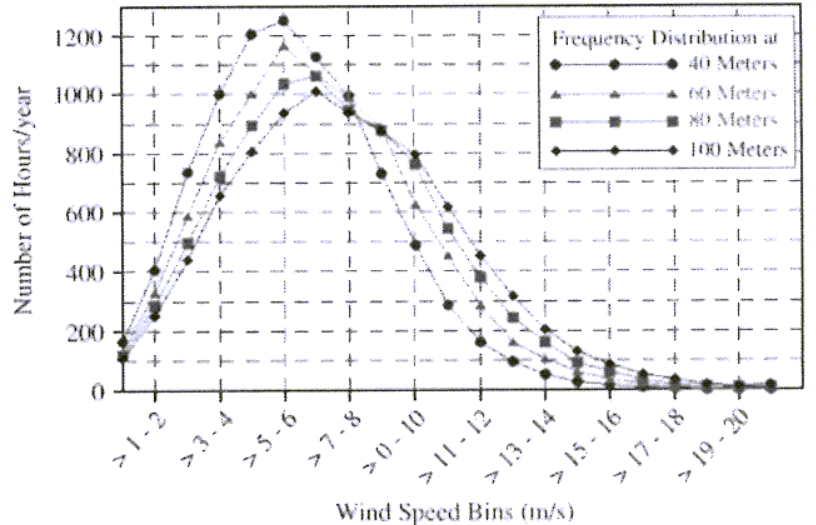

Fig. 5. Wind frequency distribution curves obtained using wind speed at different heights with WSC $=0.255$.

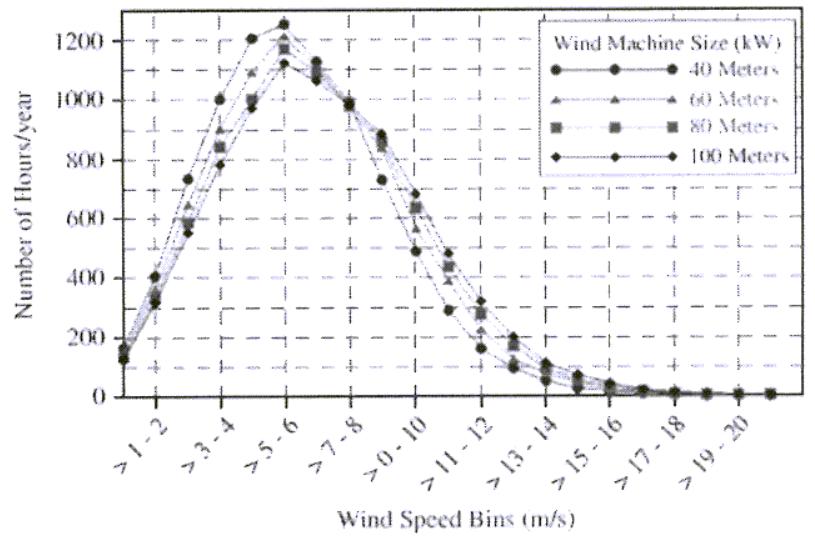

Fig. 6. Wind frequency distribution curves obtained using wind speed at different heights with WSC $=0.143$

\subsection{Wind TI characteristics}

TI is a relative indicator of turbulence and not an absolute value. It is calculated, as given in [14], by the following equation:

$\mathrm{TI}=\frac{\sigma}{V}$,

where $\sigma$ is the standard deviation of the wind speed data sample and $V$ is the mean wind speed. The half hourly and monthly average TIs at the 20,30 and $40 \mathrm{~m}$ level calculated using $10 \mathrm{~min}$ average wind speeds and corresponding standard deviation are provided in Figs. 7 and 8, respectively. Higher values of TI are observed during day time and lower during nighttime, as can be seen from Fig. 7. Similarly smaller values of TI were observed during November to March and bit higher during rest of the month. Further more, at $20 \mathrm{~m} \mathrm{AGL}$ minimum of $13 \%$ TI was observed in January and a maximum of $21 \%$ in October. In general higher values of TI were noticed at lower elevation compared to higher as it is clear from 
Figs. 7 and 8 . The International Electro-technical Commission (IEC) wind turbine design standards specify a turbine to be designed for TI levels up to $18 \%$ in $15 \mathrm{~m} / \mathrm{s}$ winds. The TI values shown in these figures were calculated using wind speeds above $4 \mathrm{~m} / \mathrm{s}$. Hence the TI values indicate no concerns for wind energy development at this location.

\section{Wind energy yield and PCF estimation}

A hypothetical wind farm of $60 \mathrm{MW}$ installed capacity is assumed of consisting 100, 60 and 30 wind turbines of 600 , 1000 and $2000 \mathrm{~kW}$ rated power at Dhulom wind mast site. The 10-min average wind speed at $40 \mathrm{~m}$ and WSCs of 0.255

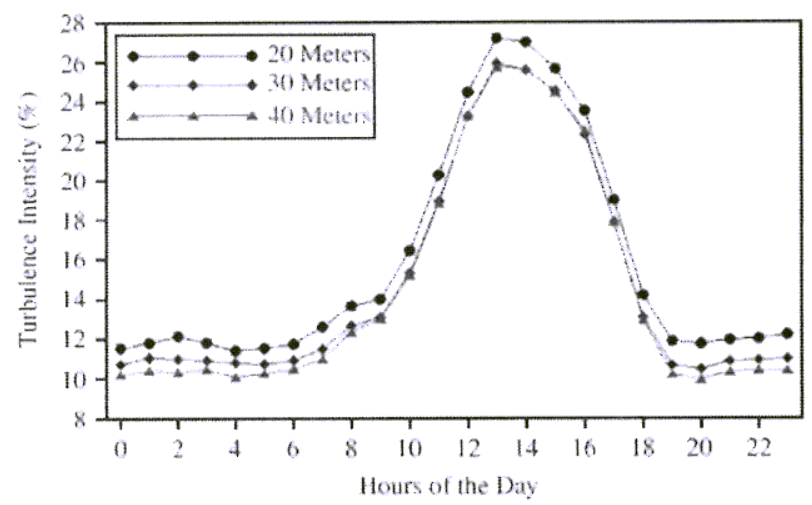

Fig. 7. Variation of turbulence intensity values during $24 \mathrm{~h}$ of the day.

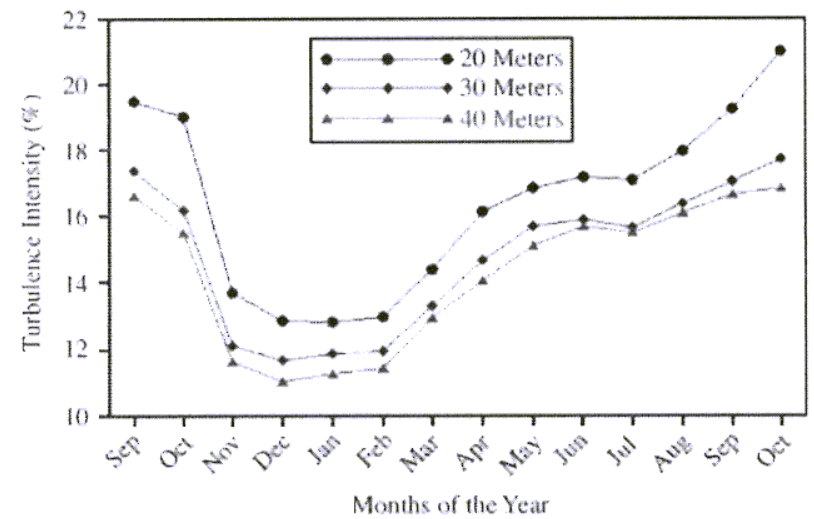

Fig. 8. Seasonal variation of turbulence intensity at Dhulom. and 0.14 were used to calculate the wind speed at $50-100 \mathrm{~m}$ heights. For energy yield calculation a program was developed in MS Excel which requires frequency distribution, wind power curves and number of wind turbines to provide energy yield and PCF of the wind power plant. Three types of wind turbines from DeWind were used for energy yield and PCF estimation. The technical information of the wind turbines given in Table 4 and the wind power curves shown in Fig. 9 were obtained from Refs. [15-17].

The energy yield obtained from a wind farm of $60 \mathrm{MW}$ installed capacity developed using 100 wind machines of $600 \mathrm{~kW}$ rated power is given in Table 5. Higher values of energy were obtained at different heights with wind speed data estimated using WSC $=0.255$ compared to that with WSC $=0.143$, as seen from Table 5. For a change of height of $10 \mathrm{~m}$ from 60 to $70 \mathrm{~m}$, see Table 6 , the AEY increases by $8 \%, 7.9 \%$ and $8.3 \%$ from wind farms developed using 100 , 60 and 30 wind turbines of 600,1000 and $2000 \mathrm{~kW}$ rated power each, respectively.

Wind power PCFs were obtained by dividing the actual annual energy yield by the rated annual energy yield and the resulting values are summarized in Table 7 . Higher PCFs were found for wind farms developed using smaller wind turbines compared to those with larger ones. Furthermore, the PCF also increases with an increase in hub-height. In addition to above, higher value of WSC resulted into larger PCFs, as can be seen from Table 7 . For WSC $=0.255$, the PCF was found to vary between $28.85 \%$ and $45.56 \%$ corresponding to hub-heights of 40 and $100 \mathrm{~m}$, respectively.

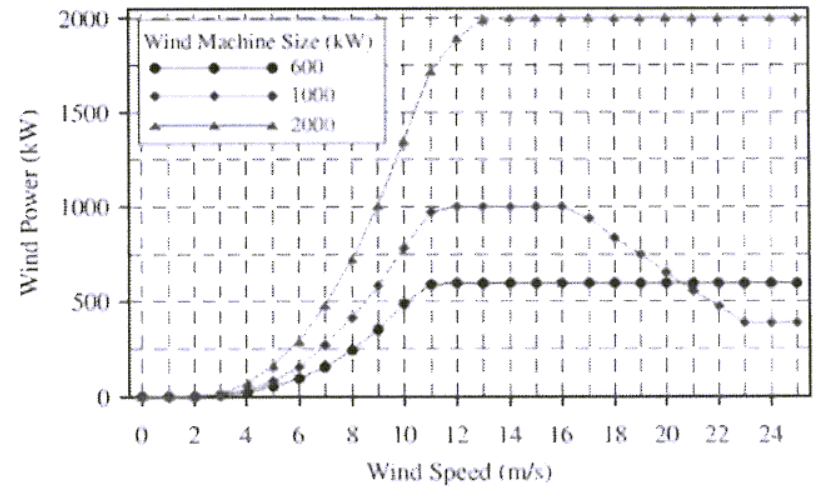

Fig. 9. Wind power curves for wind turbines from DeWind.

Table 4

Technical data of wind machines from DeWind

\begin{tabular}{|c|c|c|c|c|c|c|}
\hline Wind machine & $\begin{array}{l}\text { Cut-in speed } \\
(\mathrm{m} / \mathrm{s})\end{array}$ & $\begin{array}{l}\text { Cut-out speed } \\
(\mathrm{m} / \mathrm{s})\end{array}$ & $\begin{array}{l}\text { Rated speed } \\
(\mathrm{m} / \mathrm{s})\end{array}$ & $\begin{array}{l}\text { Survival speed } \\
(\mathrm{m} / \mathrm{s})\end{array}$ & $\begin{array}{l}\text { Rated output } \\
\text { (kW) }\end{array}$ & $\begin{array}{l}\text { Rotor diameter } \\
\text { (m) }\end{array}$ \\
\hline D4/48 & 3 & 25 & 12 & 65 & 600 & 48 \\
\hline D6 62 & 3 & 25 & 12 & 65 & 1000 & 62 \\
\hline D8:80 & 3 & 25 & 14 & 70 & 2000 & 80 \\
\hline
\end{tabular}


Table 5

Annual energy yield from a $60 \mathrm{MW}$ installed capacity wind farm developed using wind turbines of different sizes from DeWind

\begin{tabular}{|c|c|c|c|c|c|c|}
\hline \multirow[t]{3}{*}{ Hub height (m) } & \multicolumn{6}{|c|}{ Wind turbine rated power $(\mathrm{kW})$} \\
\hline & \multicolumn{3}{|c|}{ Energy yield using $1 / 7$ th wind power law (GW h/Year) } & \multicolumn{3}{|c|}{ Energy yield using local value of $\alpha=0.255$ ( $\mathrm{GW} \mathrm{h} /$ Year) } \\
\hline & 600 & 1000 & 2000 & 600 & 1000 & 2000 \\
\hline 40 & 151.63 & - & - & 151.63 & - & - \\
\hline 50 & 163.18 & 161.94 & - & 171.87 & 170.48 & - \\
\hline 60 & 172.61 & 171.20 & 154.39 & 189.22 & 187.47 & 169.65 \\
\hline 70 & 180.67 & 179.12 & 161.79 & 204.43 & 202.29 & 183.75 \\
\hline 80 & 187.66 & 185.96 & 168.26 & 217.38 & 214.83 & 195.92 \\
\hline 90 & 194.15 & 192.31 & 174.21 & 228.81 & 225.94 & 206.91 \\
\hline 100 & 199.68 & 197.68 & 179.35 & 239.46 & 236.15 & 217.05 \\
\hline
\end{tabular}

Table 6

Percent increase in energy yield with increase in hub-height from a $60 \mathrm{MW}$ installed capacity wind farm developed using wind turbines of different sizes from DeWind

\begin{tabular}{|c|c|c|c|c|c|c|}
\hline \multirow{3}{*}{$\begin{array}{l}\text { Increase in hub } \\
\text { height }(\mathrm{m})\end{array}$} & \multicolumn{6}{|c|}{ Wind turbine rated power $(\mathrm{kW})$} \\
\hline & \multicolumn{3}{|c|}{ Energy yield using $1 / 7$ th wind power law (GW h/Year) } & \multicolumn{3}{|c|}{ Energy yield using local value of $\alpha=0.255$ ( $\mathrm{GW} \mathrm{h/Year)}$} \\
\hline & 600 & 1000 & 2000 & 600 & 1000 & 2000 \\
\hline $40-50$ & 7.62 & - & - & 13.35 & - & - \\
\hline $50-60$ & 5.77 & 5.72 & - & 10.09 & 9.97 & - \\
\hline $60-70$ & 4.67 & 4.62 & 4.79 & 8.04 & 7.90 & 8.31 \\
\hline $70-80$ & 3.87 & 3.82 & 4.00 & 6.33 & 6.20 & 6.62 \\
\hline $80-90$ & 3.46 & 3.41 & 3.54 & 5.26 & 5.17 & 5.61 \\
\hline $90-100$ & 2.85 & 2.79 & 2.95 & 4.65 & 4.52 & 4.90 \\
\hline
\end{tabular}

Table 7

Plant capacity factor (PCF) of a $60 \mathrm{MW}$ installed capacity wind farm developed using wind turbines of different sizes from DeWind

\begin{tabular}{|c|c|c|c|c|c|c|}
\hline \multirow[t]{3}{*}{ Hub height (m) } & \multicolumn{6}{|c|}{ Wind turbine rated power $(\mathrm{kW})$} \\
\hline & \multicolumn{3}{|c|}{ PCF using $1 / 7$ th wind power law $(\%)$} & \multicolumn{3}{|c|}{ PCF using local value of $\alpha=0.255(\%)$} \\
\hline & 600 & 1000 & 2000 & 600 & 1000 & 2000 \\
\hline 40 & 28.85 & & & 28.85 & & \\
\hline 50 & 31.05 & 30.81 & & 32.70 & 32.43 & \\
\hline 60 & 32.84 & 32.57 & 29.37 & 36.00 & 35.67 & 32.28 \\
\hline 70 & 34.37 & 34.08 & 30.78 & 38.89 & 38.48 & 34.96 \\
\hline 80 & 35.70 & 35.38 & 32.01 & 41.36 & 40.87 & 37.27 \\
\hline 90 & 36.94 & 36.59 & 33.14 & 43.53 & 42.98 & 39.36 \\
\hline 100 & 37.99 & 37.61 & 34.12 & 45.56 & 44.93 & 41.29 \\
\hline
\end{tabular}

\section{Conclusions}

The WSCs and air density values presented in this paper will be an addition to the literature because these are estimated using actual measurements for the first time at Dhulom. The WSCs were calculated using precise measurements of wind speeds at three heights AGL. The air density values were calculated using the surface temperature and pressure measurements. The TIs were calculated using ten minutes average wind speeds and corresponding standard deviations. The findings of the present study can be summarized as follows:
- The hypothesis that the wind speed increases with height, was established from the measured values of wind speed at 20,30 and $40 \mathrm{~m} \mathrm{AGL}$. The average wind speeds at above-mentioned heights were $5.1,5.5$ and $5.9 \mathrm{~m} / \mathrm{s}$.

- The study recommends a value of WSC of 0.255 for the calculation of wind speed at different heights if wind measurements are available at one height. No set pattern was found in the mean annual values of WSC during different years of data collection period.

- No regular seasonal pattern was noticed in the monthly mean values of WSC. However, highest values were found in October and lowest in August. Since the WSCs are 
influenced by the season, so for accurate calculations of wind speed at different heights or for any other application, monthly mean values of WSCs are recommended.

- For all practical applications in Dhulom area, a mean value of air density of $1.06 \mathrm{~kg} / \mathrm{m}^{3}$ is recommended.

- The WSCs directly affect the energy yield and PCF and hence should be chosen carefully if wind measurements at different heights are not available at the site of interest.

- The annual frequency distribution analysis showed that at a hub-height of $40 \mathrm{~m}$, the wind turbines with cut-inspeed of $4 \mathrm{~m} / \mathrm{s}$ can produce energy for $74 \%$ of the time and $83 \%$ of the times with a hub-height of $100 \mathrm{~m}$.

- Higher energy yields and PCFs were obtained from wind speeds cal for $50 \mathrm{~m}$ hub height calculated using WSC $=0.255$ compared to that with $\mathrm{WSC}=0.143$. More than $40 \%$ of PCFs can be achieved from wind power plants, if developed, at Dhulom.

- For wind speeds of greater than $4.0 \mathrm{~m} / \mathrm{s}$, the monthly mean TIs were found to be less than $25 \%$ which shows that wind turbines have good chance of survival at this location. Moreover, seasonal and diurnal patterns were observed with higher values during summer season and daytime and lower during rest of the season and hours, respectively.

\section{References}

[1] Hall T, Smith B. US DOE-EPRI wind turbine verification program. TVP News Bulletin Issue 5, April 2000.

[2] Oklahama Wind Power Initiative, Wind summary Hobart's KTJS sensors tower at 40,70 and $100 \mathrm{~m}$. May 2002 .
[3] Smith K, Randall G, Malcolm D, Kelley N, Smith B. Evaluation of wind shear patterns at midwest wind energy facilities. National Renewable Energy Laboratory, NREL/CP-500-32492, WINDPOWER Conference 2002, Portland, Oregon.

[4] Sandia National Laboratories. New Mexico wind resource assessment. Global Energy Concepts, LLC, February 2003

[5] Farrugia RN. The wind shear exponent in a Mediterrancan island climate. Renewable Energy 2003;28:647-53.

[6] Sisterton DL, Hicks BB, Coulter RL, Wesely ML. Difficulties in using power laws for wind energy assessment. Sol Energy 1983;31(2): $201-4$.

[7] Ansari J, Madni IK, Bakhsh H. Saudi Arabian wind energy Atlas. Riyadh, Saudi Arabia: KACST; 1986. p. 1-27.

[8] Rehman S. Prospects of wind farm development in Saudi Arabia. Renewable Energy 2004;30(3):447-63.

[9] Rehman S. Wind energy resource assessment for Yanbo, Saudi Arabia. Energy Convers Manage 2004:45(13-14):2019-32

[10] Rehman S, Aftab A. Assessment of wind energy potential for coastal locations of the Kingdom Saudi Arabia. Energy 2004;29: 1105-15.

[11] Rehman S, Halawani TO. Statistical characteristics of wind in Saudi Arabia. Renewable Energy 1994;4(8):949-56.

[12] Al-Abbadi NM. Alawaji SH, Eugenio NN. Wind energy resource assessment: a three year experience. In: Windpower 1997 proceedings. annual conference of the American Wind Energy Association, AWEA, Austin, Texas; June 15-18, 1996. p. 533-41.

[13] Al-Abbadi NM. Wind energy resource assessment for five locations in Saudi Arabia. Renewable Energy 2005;30:1489-99.

[14] Wind resource assessment handbook, fundamentals for conducting a successful monitoring program. AWS Scientific Inc., CESTM, 251 Fuller Road, Albany, NY 12203, NREL subcontract no. TAT-515283-01, April 1997.

[15] DeWind, Publication, D4 $600 \mathrm{~kW}$ wind machine technical description, 〈http:/www.dewind.de/en/downloads/D4-600-100-eng.pdf〉.

[16] DeWind, Publication, D6 $1000 \mathrm{~kW}$ wind machine technical description, 〈http:/www.dewind.de/en/downloads/D6-1000-100-eng.pdf 〉.

[17] DeWind, Publication, D8 $2000 \mathrm{~kW}$ wind machine technical description, $\langle$ http:/www.dewind de/en/downloads/D8-2000-100-eng.pdf 〉. 